\title{
Experimental Investigation on the Shear Behavior of Interface between High Plastic Clay and Concrete
}

\author{
Yumeng Zhu $\mathbb{D}^{1,2}$ Guoying Li, ${ }^{1,3}$ Zhankuan Mi, ${ }^{1,3}$ Kuangmin Wei, ${ }^{1,3}$ and Ziyu Chen $\mathbb{D}^{1,3}$ \\ ${ }^{1}$ Geotechnical Engineering Department, Nanjing Hydraulic Research Institute, Nanjing 210029, China \\ ${ }^{2}$ College of Civil Engineering and Communication, Hohai University, Nanjing 210098, China \\ ${ }^{3}$ Key Laboratory of Failure Mechanism and Safety Control Techniques of Earth-Rock Dam Ministry of Water Resources, \\ Nanjing 210029, China \\ Correspondence should be addressed to Yumeng Zhu; zhuym0210@163.com
}

Received 26 October 2021; Revised 22 December 2021; Accepted 12 January 2022; Published 28 January 2022

Academic Editor: Shengwen Tang

Copyright (c) 2022 Yumeng Zhu et al. This is an open access article distributed under the Creative Commons Attribution License, which permits unrestricted use, distribution, and reproduction in any medium, provided the original work is properly cited.

\begin{abstract}
The Lianghekou earth core rockfill dam to be built in China will be the third highest rockfill dam in the world. This study presents the results of a series of direct shear tests between high plastic clay and concrete to study the shear behavior of contact clayconcrete cushion interface of Lianghekou dam. Results showed that water content and normal stress are significant factors affecting the shear behavior of the interface. The higher shear strength is related to lower water content and higher normal stress, and the shear strength can be formulated by the bifold-line type Mohr-Coulomb strength criterion. It is also found that the interface exhibits mainly two kinds of shear failure modes, that is, sliding failure along the concrete surface and shear failure in the clay matrix nearby the interface. Moreover, a nonlinear elastic model is proposed to simulate the shear behavior of the interface, of which parameters can be quickly estimated by water content. The simulation of the model is compared with the experimental results, and the results show that the model is reasonable and practical.
\end{abstract}

\section{Introduction}

Earth core rockfill dam (ECRD) is widely used in the world due to its low cost, adaptability to complex geological conditions, and fewer restrictions in climate conditions. ECRD will occur with large shear stress and discontinuous displacement on the interface between the earth core and the concrete cushion due to their different properties [1-4]. In order to reduce the risk of leakage and uneven deformation on the interface between the core wall and concrete cushion due to direct contact shear deformation, contact clay needs to be installed between the core wall and concrete cushion, as shown in Figure 1. High plastic clay is a common soil material for contact clay in ECRD because of its good plasticity, shear strength, and impermeability.

Experimental methodology is a significant mean to investigate the stress and strain state of the soil-structure interface. Major experimental studies have shown that surface roughness, structural material, mean particle size, soil relative density, magnitude of normal stress, temperature effects, and rate of shearing influence the soil-structure interaction behavior [5-14]. Previous researchers have mainly focused on interface friction between soil and construction materials and demonstrated that soil volume deformation greatly influences soil-structure interaction behavior [15-20]. Tatsuoka and Haibara [21] performed a series of direct shear tests to evaluate the shear strength between sand and various kinds of smooth or lubricated surfaces. Feligha and Hammoud [22] also carried out laboratory tests to investigate the effect of roughness interface and texture models on friction angle between cohesive soils and steel by direct shear tests. These results indicate that the interfacial shear strength is independent of the texture surface for a given roughness. In addition, the properties of soil have an important influence with respect to interface behavior. Taha and Fall [23] results showed that OCR, dry density, and salt content of sensitive marine clay significantly affect the interface shear behavior. Hamid and Miller [24] 


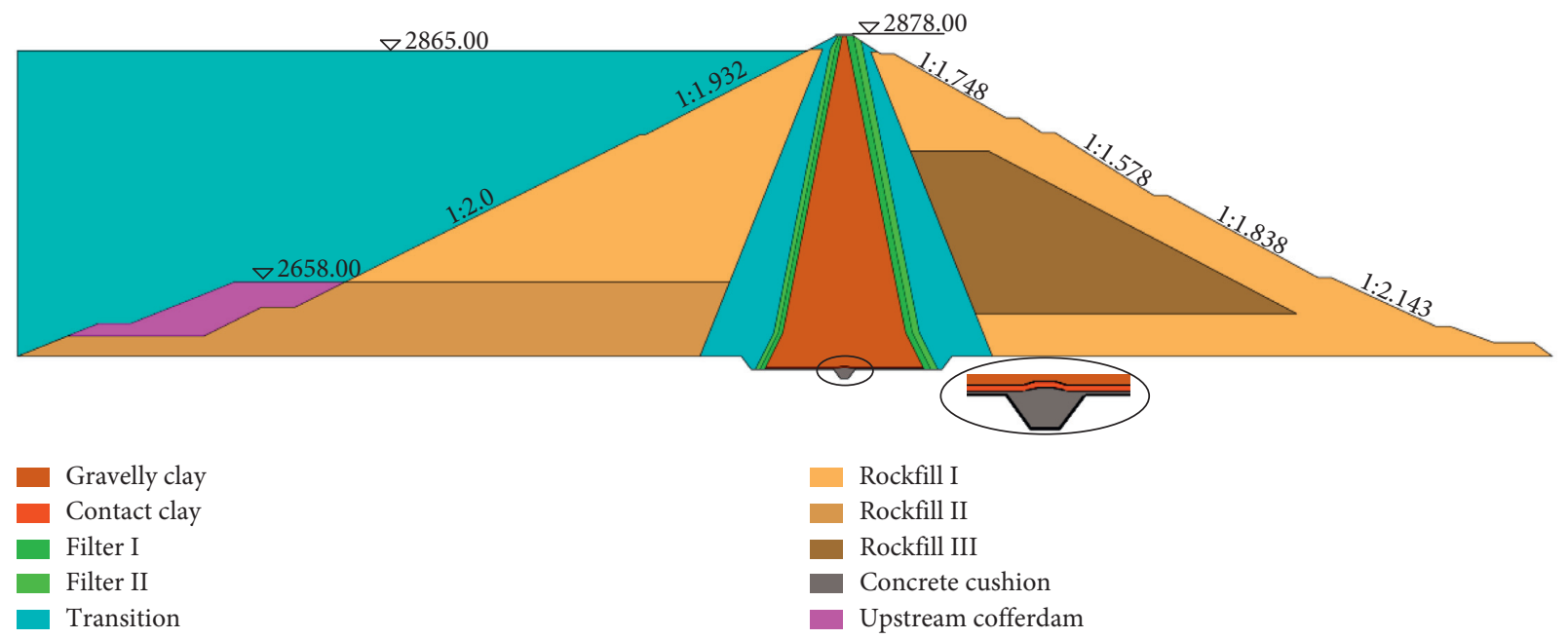

(a)

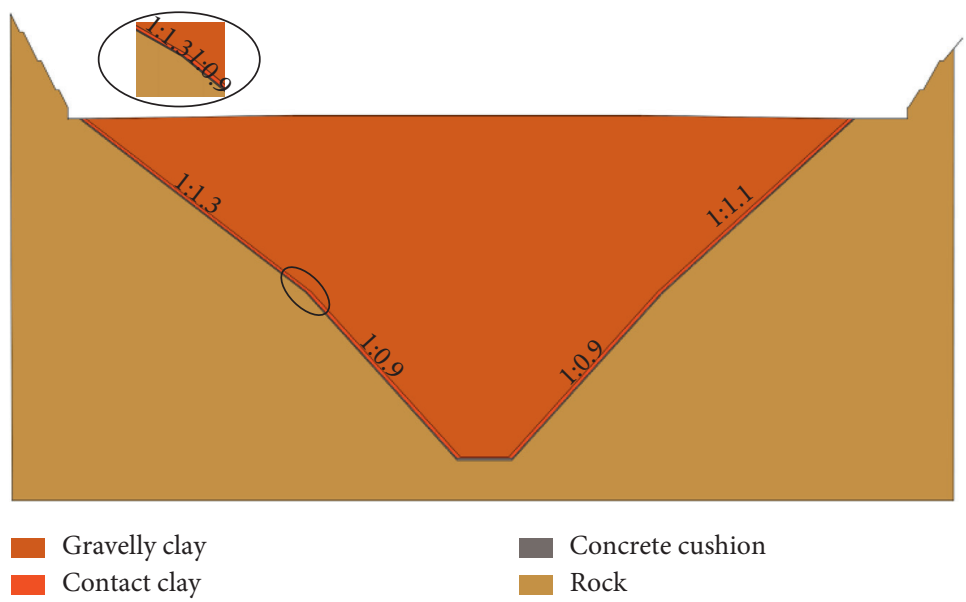

(b)

Figure 1: Typical section of the Lianghekou earth core rockfill dam. (a) Maximum cross section. (b) Maximum axial section.

concluded that peak shearing resistance is influenced by matric suction for the interface between unsaturated soil and steel plates. Furthermore, the stress path characteristic is an important issue for interfaces subjected to repeated loads [25]. Al-Douri and Poulos [26] investigated the shear behavior of various sands and sand-metal interfaces under monotonic and cyclic loading by direct shear tests. Pra-Ai and Boulon [27] described the behavior of sand-rough steel interfaces under constant normal load (CNL) and constant normal stiffness (CNS) conditions. These tests indicated that the interface shows complex sliding behavior with different factors, which is referred to as shear failure. Tsubakihara et al. [28] classified three sliding modes, namely, full sliding at the interface, shear failure within the soil, and mixed behavior. Yin et al. [29] identified three forms of slide deformation on the sand-concrete interface. The first form is a slide, which takes place along the wall surface. The second form is a slide surface located in the soil adjacent to the wall, and the third form is a failure area that consists of a lot of slide surfaces. Dejong et al. [30] found three distinct regions of deformation for sand-construct interface by monotonic and cyclic shear tests, which are slip between the interface and shear zone, shear zone itself, and the region above the shear zone. Although slide deformation of the interface is classified into three failure modes, there is still controversy over the region where the failure occurred, and how to quantitatively determine the failure mode is still inconclusive.

Nowadays, numerical methods are widely used in geotechnical engineering for design, while the reliability of numerical results depends significantly on the suitability of the constitutive model for dam materials [31]. Clough and Duncan [32] introduced a hyperbolic nonlinear elastic model to predict interfaces shear behavior. Gómez et al. [33] improved the Clough and Duncan model for arbitrary stress path directions, while it does not incorporate a better formulation for the volumetric interface behavior. Therefore, new models should be developed to model the important volumetric normal behavior of interfaces. In recent years, a large number of elastoplastic models have been proposed. Navayogarajah et al. [34] adopted the hierarchical single surface approach and the elastoplastic theory to simulate 
associative, nonassociative, and strain-softening behavior during monotonic and cyclic loading. Shahrour and Rezaie [35] proposed an elastoplastic constitutive model with two bounding surfaces to be checked over cyclic tests. Liu et al. [36] developed an elastoplastic constitutive model for the soil-structure interface that uses critical state concept and generalized plasticity approach. These results showed that interface shear behavior during monotonic and cyclic loading could be predicted reasonably. However, all the aforementioned constitutive models are based on the twodimensional behavior of the interface, whereas there are many soil-structure systems that can undergo complex three-dimensional loading [37]. Fakharian and Evgin [38] extended the Navayogarajah et al. model [34] to predict the three-dimensional behavior of the interface under both constant normal stress and constant normal stiffness conditions. The elastoplastic model was modified to capture the three-dimensional (3D) behavior of soil-structure interfaces by Liu et al. [39]. Rehman and Zhang [40] developed a threedimensional elastoplastic damage model that takes into account coupling effect, volumetric change behavior, and aeolotropy.

Up to now, there has been very limited study on contact clay-concrete cushion interface in the ECRD. For the ECRD, concrete cushion roughness, stress state, soil density, and water content have a great influence on the shear behavior of interface, so it is necessary to test the behavior of high plasticity clay-concrete with different water content. In this study, high plasticity clay from Lianghekou dam is selected as a test object, which is located in Sichuan province, China. A series of monotonic direct shear tests are conducted on the clay-concrete interface to study the shear behavior of the clay-concrete interface. A nonlinear elastic model is modified to simulate the shear stress and normal deformation of the interface. The aim of this study is to comprehensively analyse and clarify the frictional behavior between high plasticity clay and concrete and the influence of water content on contact clay-concrete cushion interface shear behavior. The current study is helpful to better understanding of clay-concrete interface in ECRD.

\section{Description of Tests}

2.1. Apparatus. The interface tests adopt three-dimensional shear apparatus. The test equipment is mainly composed of a shear box, thrust driving equipment, normal stress loading device, and control measurement system, in which the normal stress can reach 1.2 MPa, the maximum shear thrust of the controller is $2.4 \mathrm{kN}$, the maximum stroke is $10 \mathrm{~cm}$, and the shear rate is $05 \mathrm{~mm} / \mathrm{s}$. The normal stress is applied to the top surface of the sample, and a normal displacement sensor is installed. The corresponding sensors can automatically measure the stress and displacement with an accuracy of $2 \%$ FS (full scale). Figure 2 shows a top view of the three-dimensional direct shear apparatus. For this study, the conventional monotone shear path was adopted; that is, the sample was shear along the $X$ direction. The soil was placed in the upper shear box, and solid was used to replace the lower shear box as Chen et al. [41] suggested, as shown in Figure 3.
2.2. Material. The high plasticity clay is reddish-brown, and the particles are subangular. Its grain size distribution is shown in Figure 4, and the basic physical properties are shown in Table 1. Through X-ray diffraction analysis, the main component of the soil sample is $\mathrm{SiO} 2$, which is mixed with a small amount of CaAl2Si2O $8 \cdot 4 \mathrm{H} 2 \mathrm{O}$.

2.3. Test Programs. The effect of water content (12.5\%, $14.5 \%, 16.5 \%$, and $18.5 \%)$ and normal stress $(200 \mathrm{kPa}$, $400 \mathrm{kPa}, 600 \mathrm{kPa}$, and $800 \mathrm{kPa}$ ) is included in the scope of the present study. The reconstituted high plasticity clay specimens were used, and specimens were compacted to a target compaction degree of $98 \%$ at each water content. In order to measure the normal deformation caused only by shear stress in the direct shear test, normal load was applied to the upper shear box until the normal deformation became stable. In this study, the specified normal load is applied to the sample, and the normal deformation is recorded. When the normal deformation rate is less than $0.005 \mathrm{~mm} / \mathrm{h}$, the sample is considered to be stable, and the average consolidation time is about $26.1 \mathrm{~h}$. A shear deformation rate of $0.8 \mathrm{~mm} / \mathrm{min}$ (shear strain rate of $0.013 \% / \mathrm{min}$ ) was used in this study by ASTM D5321 [42].

It should be noted that the roughness has a significant influence on the mechanical properties of the soil-concrete interface [43]. The smooth concrete plate was used in this study to simulate the slip surface concrete cushion in the field. To avoid complexity, concrete plates always have a constant surface roughness throughout the experimental program.

A series of direct shear tests were taken to measure the shear strength of high plasticity clay, which comply with ASTM D3080 [44]. The test schemes are listed in Table 2.

\section{Test Results}

3.1. Shear Behavior. Figure 5 shows test results of high plasticity clay-concrete interface. The shear stress-shear strain relationship of the interface shows a hyperbolic trend and exhibits hardening for most specimens. The shear strain at failure increases with increasing normal stress under the same water content. In summary, higher water content is related to lower shear strength, especially for higher normal stress.

It is known that the positive normal displacement is related to shear compression, and the negative normal displacement is related to shear dilation. The test results show that shear dilation appears to occur on specimens with low normal stress and water content. The interface with higher water content $(\geq 14.5 \%)$ subjected to a normal pressure of over $400 \mathrm{kPa}$ shows no dilation, while the interface with $12.5 \%$ water content shows no dilation when it is subjected to normal pressure of $600 \mathrm{kPa}$ and $800 \mathrm{kPa}$. With the increase of the normal stresses and water content, the shear behavior exhibits a shear contraction trend, and the contraction trend is more obvious than the dilation trend.

For interface tests, the interface dilation angle $\psi$ is calculated by [45-47] 


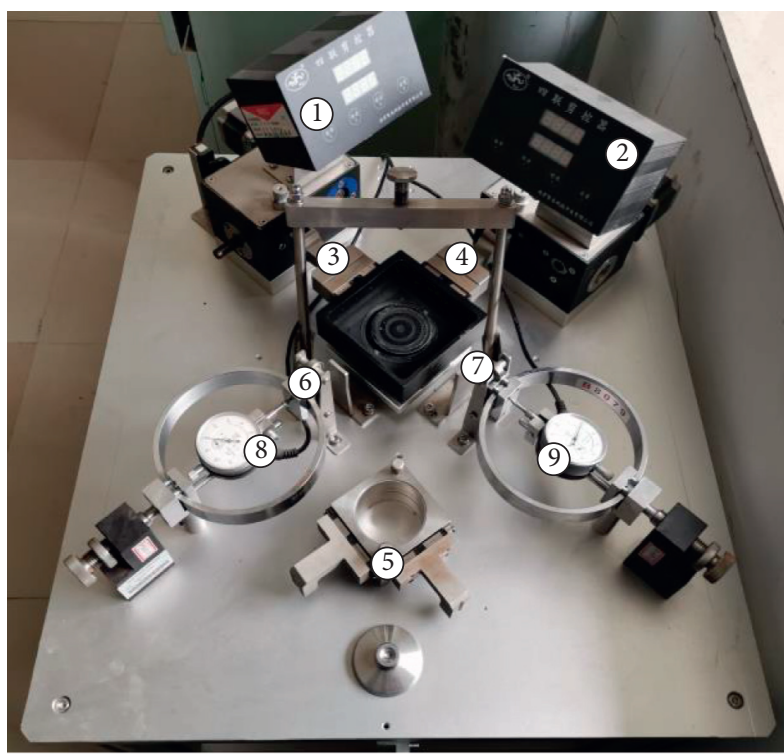

(a)

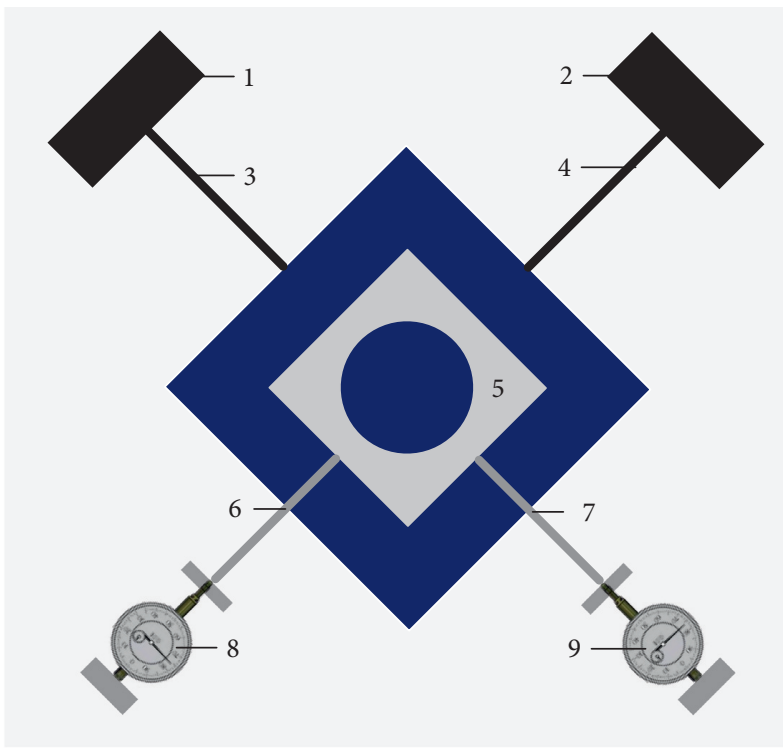

(b)

Figure 2: Top view of three-dimensional direct shear apparatus. (a) Picture of the apparatus. (b) Schematic view of the apparatus.

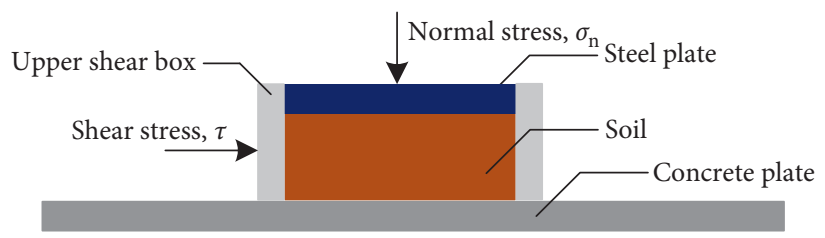

FIGURE 3: Schematic view of the soil-construct interface.

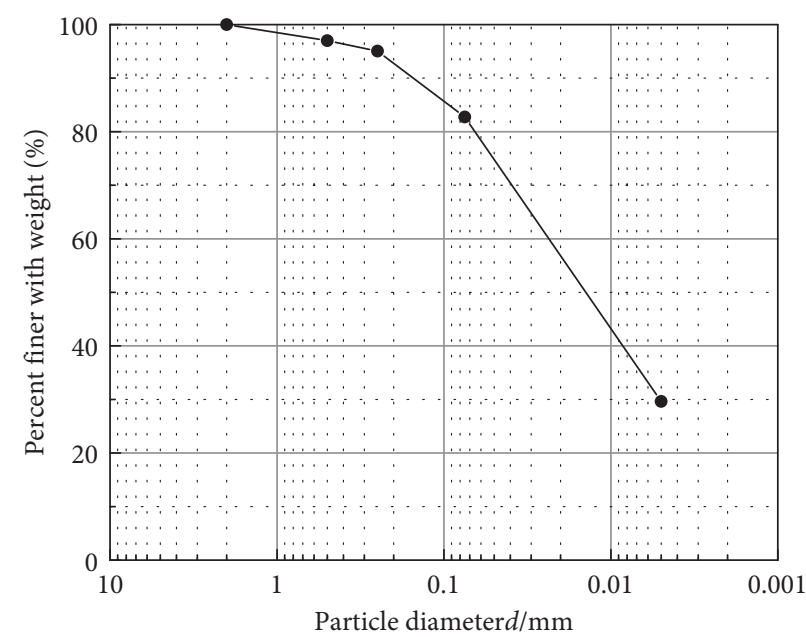

FIGURE 4: Grain size distribution of clay used in the tests.

$$
\psi=\tan ^{-1}\left(-\frac{\mathrm{d} v}{\mathrm{~d} u}\right),
$$

where $d v$ and $d u$ are increments of horizontal and normal displacements, respectively. Dilation angles of the interface were plotted versus shear strain in Figure 6 . It can be seen that dilatancy angle first increases and then decreases with the increase of shear strain under low normal stress $(\leq 400 \mathrm{kPa})$, while presenting an opposite trend under high stress $(\geq 600 \mathrm{kPa})$. Compared to interface with water content of $12.5 \%$, interface with other types of water contents shows a similar trend. The maximum dilation angles for interface with water content of $12.5 \%$ under normal stress of $200 \mathrm{kPa}$ and $400 \mathrm{kPa}$ are $15.25^{\circ}$ and $13.74^{\circ}$, respectively. The 
TABLE 1: Indices of the properties of high plasticity clay.

\begin{tabular}{|c|c|c|c|c|c|c|c|}
\hline $\begin{array}{l}\text { Median diameter } \\
d_{30}(\mathrm{~mm})\end{array}$ & $\begin{array}{l}\text { Limit of particle } \\
\text { size } d_{60}(\mathrm{~mm})\end{array}$ & $\begin{array}{l}\text { Specific } \\
\text { gravity } G\end{array}$ & $\begin{array}{l}\text { Liquid limit } \\
\text { (\%) }\end{array}$ & $\begin{array}{c}\text { Plastic limit } \\
(\%)\end{array}$ & $\begin{array}{c}\text { Plastic } \\
\text { index }(\%)\end{array}$ & $\begin{array}{c}\text { Maximum dry density } \\
\rho_{\mathrm{dmax}}\left(\mathrm{g} \cdot \mathrm{cm}^{3}\right)\end{array}$ & $\begin{array}{c}\text { Optimal } \\
\text { water } \\
\text { content } W_{\text {op }} \\
(\%)\end{array}$ \\
\hline 0.006 & 0.026 & 2.71 & 37.5 & 15.9 & 21.6 & 1.80 & 16.5 \\
\hline
\end{tabular}

Table 2: Test schemes of this study.

\begin{tabular}{lcl}
\hline Test group & Water content $w(\%)$ & Normal stress $\sigma_{\mathrm{n}}(\mathrm{kPa})$ \\
\hline I1 & 12.5 & $200,400,600$, and 800 \\
I2 & 14.5 & $200,400,600$, and 800 \\
I3 & 16.5 & $200,400,600$, and 800 \\
I4 & 18.5 & $200,400,600$, and 800 \\
D1 & 12.5 & $200,400,600$, and 800 \\
D2 & 14.5 & $200,400,600$, and 800 \\
D3 & 16.5 & $200,400,600$, and 800 \\
D4 & 18.5 & $200,400,600$, and 800 \\
\hline
\end{tabular}

Note. I represents the direct shear test of high plasticity clay-concrete interface; D represents the direct shear test of high plasticity clay.

maximum dilation angles for interface with water content of $14.5 \%$ and $16.5 \%$ under normal stress of $200 \mathrm{kPa}$ are $11.69^{\circ}$ and $10.25^{\circ}$, respectively. In general, the maximum dilation angles decrease with increasing water content.

3.2. Shear Strength Analysis. Figure 7 shows the shear strength of high plasticity clay-concrete interface and high plasticity clay. It can be seen that the shear strength of the interface is obviously smaller than that of clay at a normal stress of $200 \mathrm{kPa}$ and $400 \mathrm{kPa}$. With the increasing normal stress, the shear strength of the interface basically coincides with the shear strength of clay itself. This indicates that the interface makes sliding failure along the concrete surface when normal stress is relatively low, while shear failure occurs in a clay matrix with high normal stress. Liu et al. [48] also obtained similar test results and proposed that the stress-strain relationship of the interface is accordingly determined by the failure mode. Figure 8 shows pictures of failed samples in interface tests and direct shear tests.

The shear strength of interface could be expressed as bifold-line type Mohr-Coulomb strength criterion:

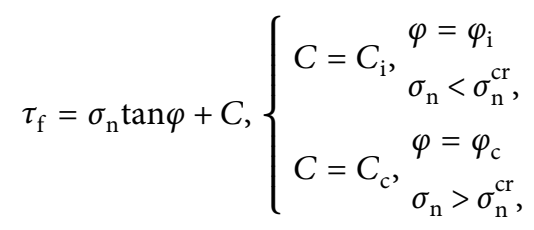

where $\varphi_{\mathrm{i}}$ and $\varphi_{\mathrm{c}}$ are the friction angle of interface and clay, $C_{\mathrm{i}}$ and $C_{\mathrm{c}}$ are the cohesion of interface and clay, and $\sigma_{\mathrm{n}}^{\mathrm{cr}}$ is the critical normal stress at the intersection of two shear failure modes.

\section{Determination of Constitutive Model Parameters}

Desai et al. [49] proposed the thin-layer element formulation, which can be written as

$$
\left\{\begin{array}{c}
\mathrm{d} \sigma_{\mathrm{n}} \\
\mathrm{d} \tau
\end{array}\right\}=\left[\begin{array}{cc}
E_{\mathrm{n}} & G_{\mathrm{sn}} \\
E_{\mathrm{ns}} & G_{\mathrm{s}}
\end{array}\right]\left\{\begin{array}{c}
\mathrm{d} \varepsilon_{\mathrm{n}} \\
\mathrm{d} \gamma
\end{array}\right\},
$$

where $E_{\mathrm{n}}$ and $G_{\mathrm{s}}$ are the normal modulus and shear modulus of the interface, which are controlled by normal stress, construction materials, types of soil, and initial density of soil; $E_{\mathrm{ns}}$ and $G_{\mathrm{sn}}$ are the coupling terms. Tangential strain caused by normal stress is generally not considered in simple shear test and direct shear test; thus, $G_{\mathrm{sn}}=0[50,51]$. With the hypothesis that the moduli are stress path independent, $E_{\mathrm{n}}, G_{\mathrm{s}}$, and $E_{\mathrm{ns}}$ can be determined by the oedometric compression test and direct shear test [52-54].

For thin-layer interface element, normal strain and shear strain can be expressed by

$$
\left\{\begin{array}{c}
\mathrm{d} \varepsilon_{\mathrm{n}} \\
\mathrm{d} \gamma
\end{array}\right\}=\left[\begin{array}{cc}
1 / t & 0 \\
0 & 1 / t
\end{array}\right]\left\{\begin{array}{l}
\mathrm{d} v \\
\mathrm{~d} u
\end{array}\right\},
$$

where $t$ is the thickness of the interface element.

4.1. Shear Modulus $G_{s}$. Shear modulus reflects the shear characteristics of the interface, and a hyperbola is used to approximate empirical experimental data from interface tests:

$$
\tau=\frac{\gamma}{a_{1}+b_{1} \gamma}
$$

where $a_{1}$ and $b_{1}$ are the parameters of the hyperbolic model. Similar to the model of Clough and Duncan [32], $a_{1}$ and $b_{1}$ can be expressed by

$$
\begin{aligned}
& a_{1}=\frac{1}{G_{\mathrm{si}}}=\frac{1}{K_{1} P_{\mathrm{a}}\left(\sigma_{\mathrm{n}} / P_{\mathrm{a}}\right)^{\mathrm{n}_{1}}} \\
& b_{1}=\frac{1}{\tau_{\mathrm{u}}}=\frac{R_{\mathrm{f}}}{\tau_{\mathrm{f}}}
\end{aligned}
$$

where $G_{\mathrm{si}}$ is the initial shear modulus, $\tau_{\mathrm{u}}$ is the shear strength corresponding to the ultimate state, and $K_{1}, n_{1}$, and $R_{\mathrm{f}}$ are soil parameters. 

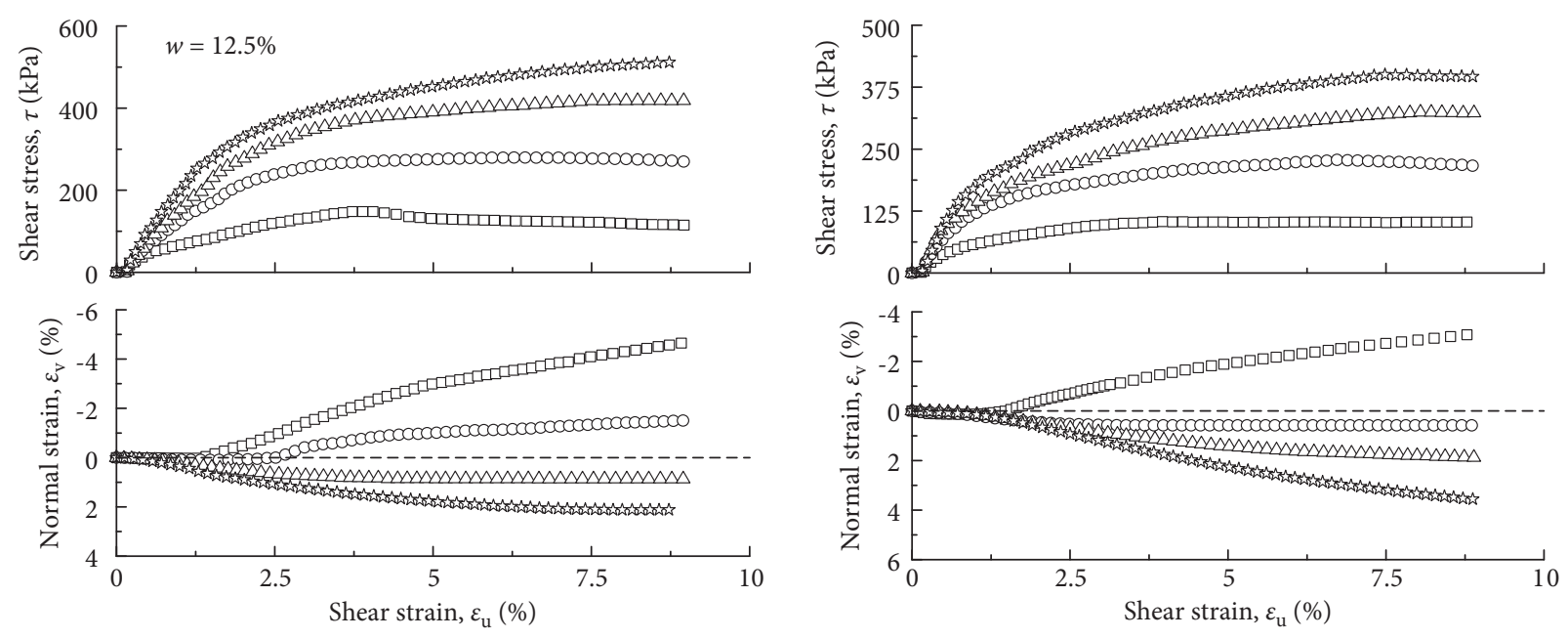

$$
\begin{array}{lll}
\square \sigma_{\mathrm{n}}=200 \mathrm{kPa} & \triangle \sigma_{\mathrm{n}}=600 \mathrm{kPa} \\
\bigcirc \sigma_{\mathrm{n}}=400 \mathrm{kPa} & \text { ¿ } \sigma_{\mathrm{n}}=800 \mathrm{kPa}
\end{array}
$$

$$
\begin{aligned}
& \square \sigma_{\mathrm{n}}=200 \mathrm{kPa} \\
& \bigcirc \sigma_{\mathrm{n}}=400 \mathrm{kPa}
\end{aligned}
$$

(a)
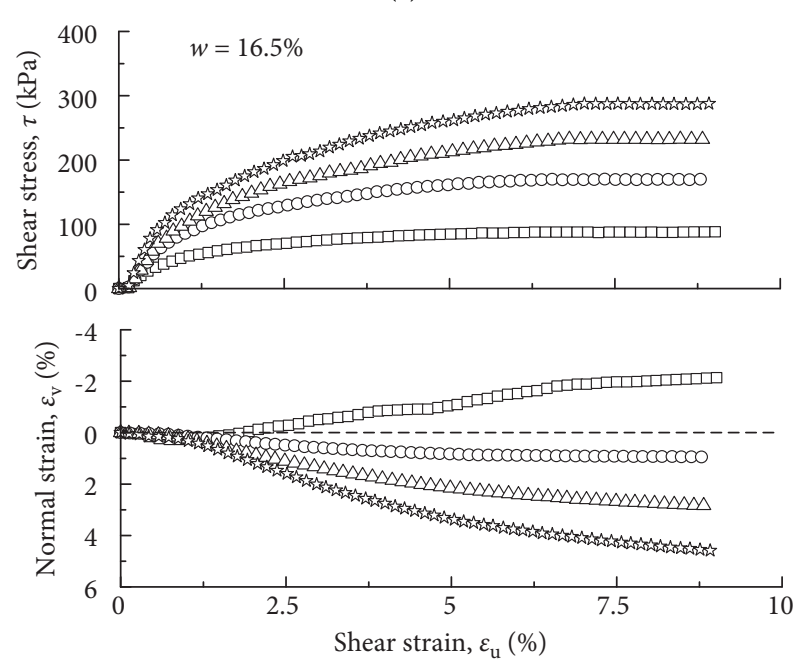

$$
\begin{array}{ll}
\square \sigma_{\mathrm{n}}=200 \mathrm{kPa} & \triangle \sigma_{\mathrm{n}}=600 \mathrm{kPa} \\
\bigcirc \sigma_{\mathrm{n}}=400 \mathrm{kPa} & \text { ㅎ } \sigma_{\mathrm{n}}=800 \mathrm{kPa}
\end{array}
$$

(c)
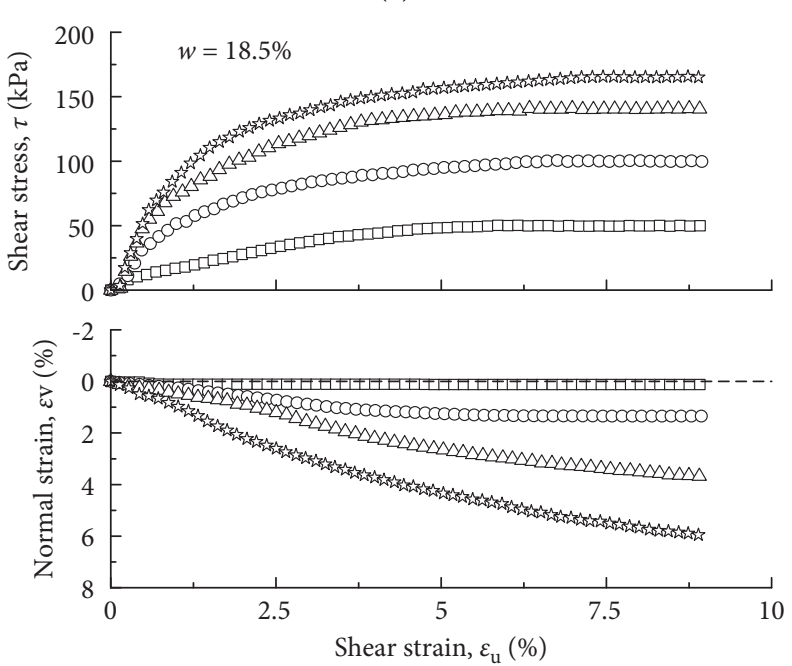

$$
\begin{aligned}
& \square \sigma_{\mathrm{n}}=200 \mathrm{kPa} \\
& \bigcirc \sigma_{\mathrm{n}}=400 \mathrm{kPa}
\end{aligned}
$$

(d)

Figure 5: Test results of high plasticity clay-concrete interface. (a) $w=12.5 \%$, (b) $w=14.5 \%$, (c) $w=16.5 \%$, and (d) $w=18.5 \%$.

$$
\begin{aligned}
G_{s} & =\frac{d \tau}{d \gamma}=\frac{\left(1-b_{1} \tau\right)^{2}}{a_{1}} \\
& =\left(1-\frac{R_{f} \tau}{\tau_{f}}\right)^{2} K_{1} P_{a}\left(\frac{\sigma_{n}}{P_{a}}\right)^{n_{1}}=\left\{\begin{array}{l}
\left(1-\frac{R_{f} \tau}{\left(\sigma_{n} \tan \varphi_{i}+C_{i}\right)}\right)^{2} K_{1} P_{a}\left(\frac{\sigma_{n}}{P_{a}}\right)^{n_{1}}, \quad \sigma_{n} \leq \sigma_{n}^{c r} . \\
\left(1-\frac{R_{f} \tau}{\left(\sigma_{n} \tan \varphi_{c}+C_{c}\right)}\right)^{2} K_{1} P_{a}\left(\frac{\sigma_{n}}{P_{a}}\right)^{n_{1}}, \quad \sigma_{n}>\sigma_{n}^{c r} .
\end{array}\right.
\end{aligned}
$$

There are 7 parameters required to describe the relation of shear stress and shear strain, which are $\varphi_{\mathrm{i}}, \varphi_{\mathrm{c}}, C_{\mathrm{i}}, C_{\mathrm{c}}, K_{1}$, $n_{1}$, and $R_{\mathrm{f}}$. All the parameters can be defined by the direct shear test subjected to different normal stress. 


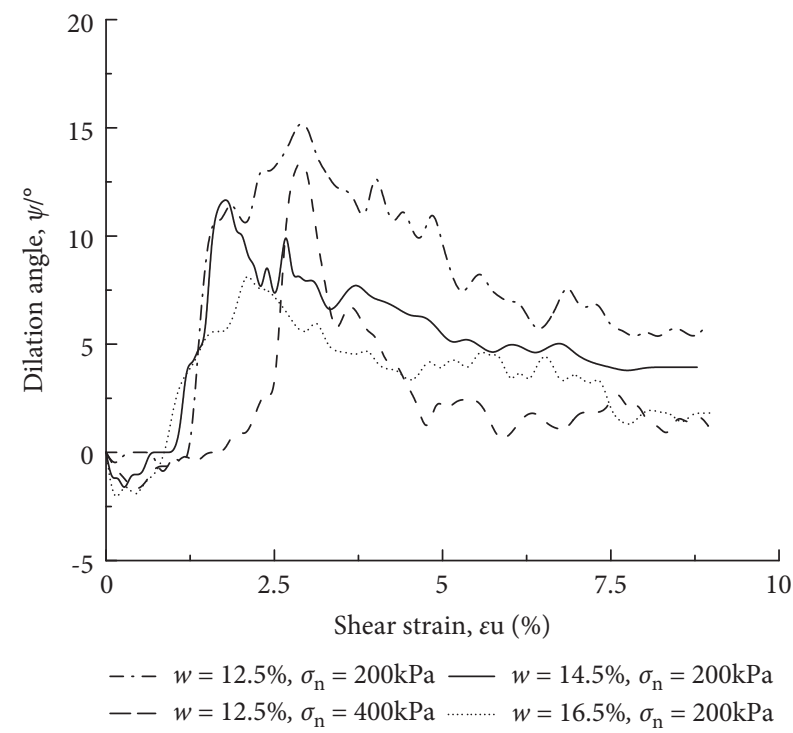

(a)

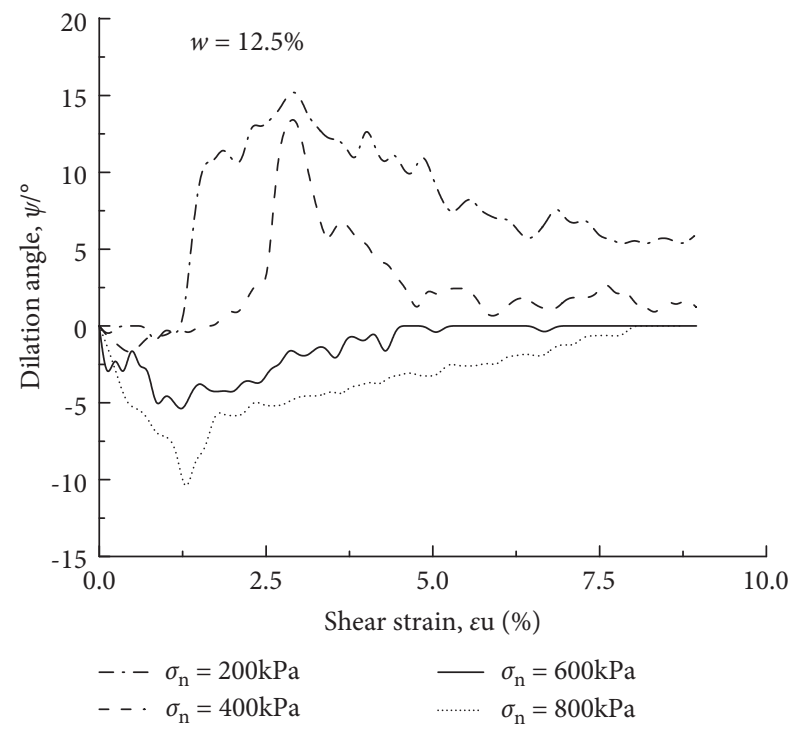

(b)

Figure 6: Variation of dilation angle with shear strain of interface. (a) Interface show shear dilation. (b) Interface with water content $12.5 \%$.

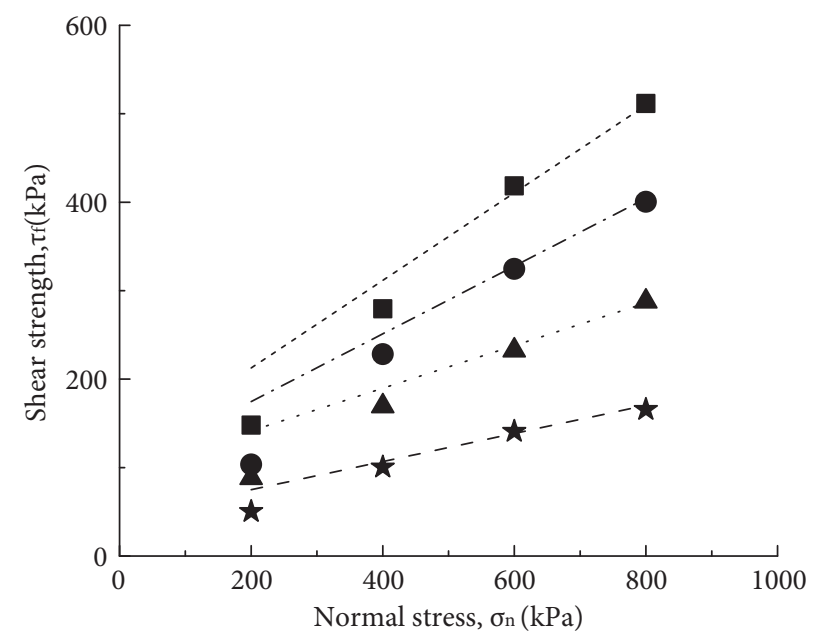

Mohr-Coulomb envelopes of clay

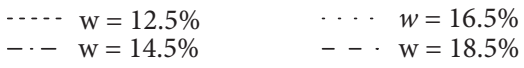

Shear strength of interface

- $\mathrm{w}=12.5 \%$

- $\mathrm{w}=14.5 \%$

- $\mathrm{W}=16.5 \%$

$\star \mathrm{W}=18.5 \%$ 
4.2. Normal Tangent Modulus $E_{n s}$. Based on direct shear test results, the relation curve of normal strain and shear strain can be fitted in the subsection of hyperbolic function and quadratic function:

$$
\varepsilon_{n s}= \begin{cases}e_{1}\left(\frac{\sigma_{n}}{P_{a}}\right)^{f_{1}}\left(\left(\frac{\sigma_{n}}{P_{a}}\right)^{k_{1}}-\gamma\right) \gamma^{n_{2}}, & \sigma_{n} \leq \sigma_{n}^{d}, \\ \frac{\gamma}{\left(\sigma_{n} / P_{a}\right)^{e_{2}}+f_{2}\left(\sigma_{n} / P_{a}\right)^{k_{2}} \gamma}, & \sigma_{n}>\sigma_{n}^{d},\end{cases}
$$

where $e_{1}, e_{2}, f_{1}, f_{2}, k_{1}, k_{2}$, and $n_{2}$ are model parameters and $\sigma_{n}^{\mathrm{d}}$ is critical normal stress of normal deformation. Shear dilation appears to occur at the interface under normal stress less than critical normal stress, and the interface appears as shear contraction under normal stress greater than critical normal stress.

Further, the relationship of incremental strains in normal and tangential directions can be derived as follows:

$$
d \varepsilon_{\mathrm{ns}}= \begin{cases}\left(e_{1} n_{2}\left(\frac{\sigma_{n}}{P_{a}}\right)^{f_{1}}\left(\frac{\sigma_{n}}{P_{a}}\right)^{k_{1}} \gamma^{n_{2}-1}-e_{1}\left(g_{1}+1\right)\left(\frac{\sigma_{n}}{P_{a}}\right)^{f_{1}} \gamma^{n_{2}}\right) d \gamma, & \sigma_{n} \leq \sigma_{n}^{d} . \\ \frac{\left(\sigma_{n} / P_{a}\right)^{e_{2}}}{\left(1-f_{2}\left(\sigma_{n} / P_{a}\right)^{k_{2}} \gamma\right)^{2}} d \gamma, & \sigma_{n}>\sigma_{n}^{d} .\end{cases}
$$

$E_{\mathrm{ns}}$ can be deduced as follows:

where $H_{1}, H_{2}, M_{1}$, and $M_{2}$ are defined as follows:

$$
E_{\mathrm{ns}}=\frac{d \tau}{d \varepsilon_{\mathrm{ns}}}=\frac{d \tau}{d \gamma} \cdot \frac{d \gamma}{d \varepsilon_{\mathrm{ns}}}= \begin{cases}H_{1} / M_{1} & \sigma_{n} \leq \sigma_{n}^{d} \\ H_{1} / M_{2} & \sigma_{n}^{d}<\sigma_{n} \leq \sigma_{n}^{\mathrm{cr}}, \\ H_{2} / M_{2} & \sigma_{n}>\sigma_{n}^{\mathrm{cr}}\end{cases}
$$

$$
\begin{aligned}
H_{1} & =\left(1-\frac{\left(\sigma_{n} \tan \varphi_{i}+C_{i}\right) \tau}{R_{f}}\right)^{2} K_{1} P_{a}\left(\frac{\sigma_{n}}{P_{a}}\right)^{n_{1}} \sigma_{n} \leq \sigma_{n}^{\mathrm{cr}}, \\
H_{2} & =\left(1-\frac{\left(\sigma_{n} \tan \varphi_{c}+C_{c}\right) \tau}{R_{f}}\right)^{2} K_{1} P_{a}\left(\frac{\sigma_{n}}{P_{a}}\right)^{n_{1}} \sigma_{n}>\sigma_{n}^{\mathrm{cr}}, \\
M_{1} & =\left(e_{1} n_{2}\left(\frac{\sigma_{n}}{P_{a}}\right)^{f_{1}}\left(\frac{\sigma_{n}}{P_{a}}\right)^{k_{1}} \gamma^{n_{2}-1}-e_{1}\left(g_{1}+1\right)\left(\frac{\sigma_{n}}{P_{a}}\right)^{f_{1}} \gamma^{n_{2}}\right)^{-1} \sigma_{n} \leq \sigma_{n}^{d}, \\
M_{2}= & \left(1-f_{2}\left(\sigma_{n} / P_{a}\right)^{k_{2}} \gamma\right)^{2} \\
\left(\sigma_{n} / P_{a}\right)^{e_{2}} & \sigma_{n}>\sigma_{n}^{d} .
\end{aligned}
$$

The analysis above shows that 7 parameters are required to describe the relation of normal strain and shear strain. These 7 parameters are $e_{1}, e_{2}, f_{1}, f_{2}, k_{1}, k_{2}$, and $n_{2}$.

\section{Model Simulations}

The model parameters are calibrated according to high plasticity clay-concrete interface test results, and then the results of the simulation are compared with the experimental results. The parameters for interface tests are listed in Table 3. The simulation results are show in Figure 9 together with the experimental results. It can be seen that the nonlinear elastic model could simulate the behavior of high plasticity clay-concrete interface with good accuracy.

\section{Discussions}

Hereto, a nonlinear elastic model is completely defined to describe the high plasticity clay-concrete interface deformation behavior, and all parameters can be derived from experimental tests. It can be seen from Table 4 that model parameters have a significant correlation with water content. The relationship between model parameters and water content can be fitted in linear functions and exponential 


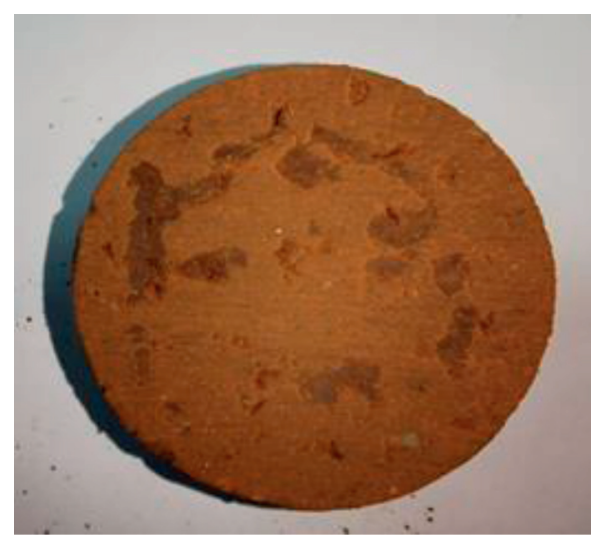

(a)

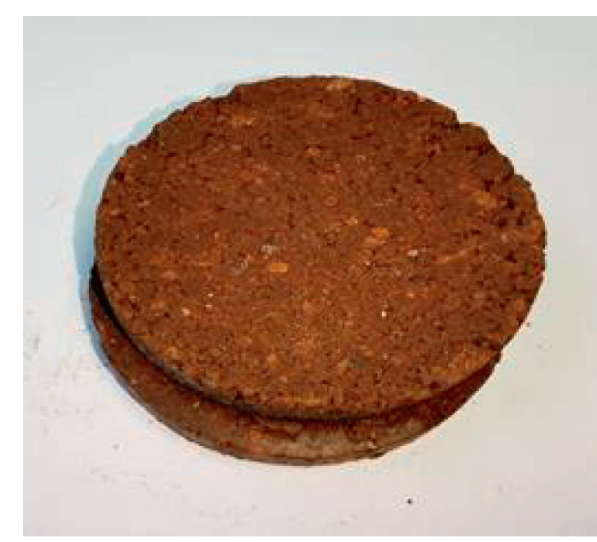

(b)

Figure 8: Pictures of failed samples. (a) Direct shear test of high plasticity clay-concrete interface. (b) Direct shear test of clay.

TABLE 3: Model parameters of interface tests.

\begin{tabular}{|c|c|c|c|c|c|c|}
\hline$\varphi_{\mathrm{i}}\left(^{\circ}\right)$ & $\varphi_{\mathrm{c}}\left({ }^{\circ}\right)$ & $C_{\mathrm{i}}(\mathrm{kPa})$ & $C_{\mathrm{c}}(\mathrm{kPa})$ & $K_{1}$ & $n_{1}$ & $R_{\mathrm{f}}$ \\
\hline \multicolumn{7}{|c|}{$w=12.5 \%$} \\
\hline 34.64 & 26.34 & 11.07 & 113.58 & 0.13 & 0.38 & 0.84 \\
\hline$e_{1}$ & $e_{2}$ & $f_{1}$ & $f_{2}$ & $k_{1}$ & $k_{2}$ & $n_{2}$ \\
\hline 0.31 & 0.94 & -1.53 & 2603.27 & 1.35 & -4.92 & 0.065 \\
\hline \multicolumn{7}{|c|}{$w=14.5 \%$} \\
\hline 29.16 & 20.96 & 6.41 & 97.99 & 0.09 & 0.494 & 0.83 \\
\hline$e_{1}$ & $e_{2}$ & $f_{1}$ & $f_{2}$ & $k_{1}$ & $k_{2}$ & $n_{2}$ \\
\hline 0.065 & 0.97 & -1.23 & 502.87 & 1.47 & -4.56 & 0.16 \\
\hline \multicolumn{7}{|c|}{$w=16.5 \%$} \\
\hline 22.59 & 13.55 & 2.17 & 93.26 & 0.07 & 0.487 & 0.82 \\
\hline$e_{1}$ & $e_{2}$ & $f_{1}$ & $f_{2}$ & $k_{1}$ & $k_{2}$ & $n_{2}$ \\
\hline 0.03 & 0.78 & -0.98 & 191.52 & 1.52 & -4.24 & 0.34 \\
\hline \multicolumn{7}{|c|}{$w=18.5 \%$} \\
\hline 13.44 & 9.03 & 1.33 & 43.24 & 0.01 & 1.34 & 0.86 \\
\hline$e_{1}$ & $e_{2}$ & $f_{1}$ & $f_{2}$ & $\mathrm{k} 1$ & $k_{2}$ & $n_{2}$ \\
\hline- & 0.58 & - & 47.36 & - & -3.55 & - \\
\hline
\end{tabular}
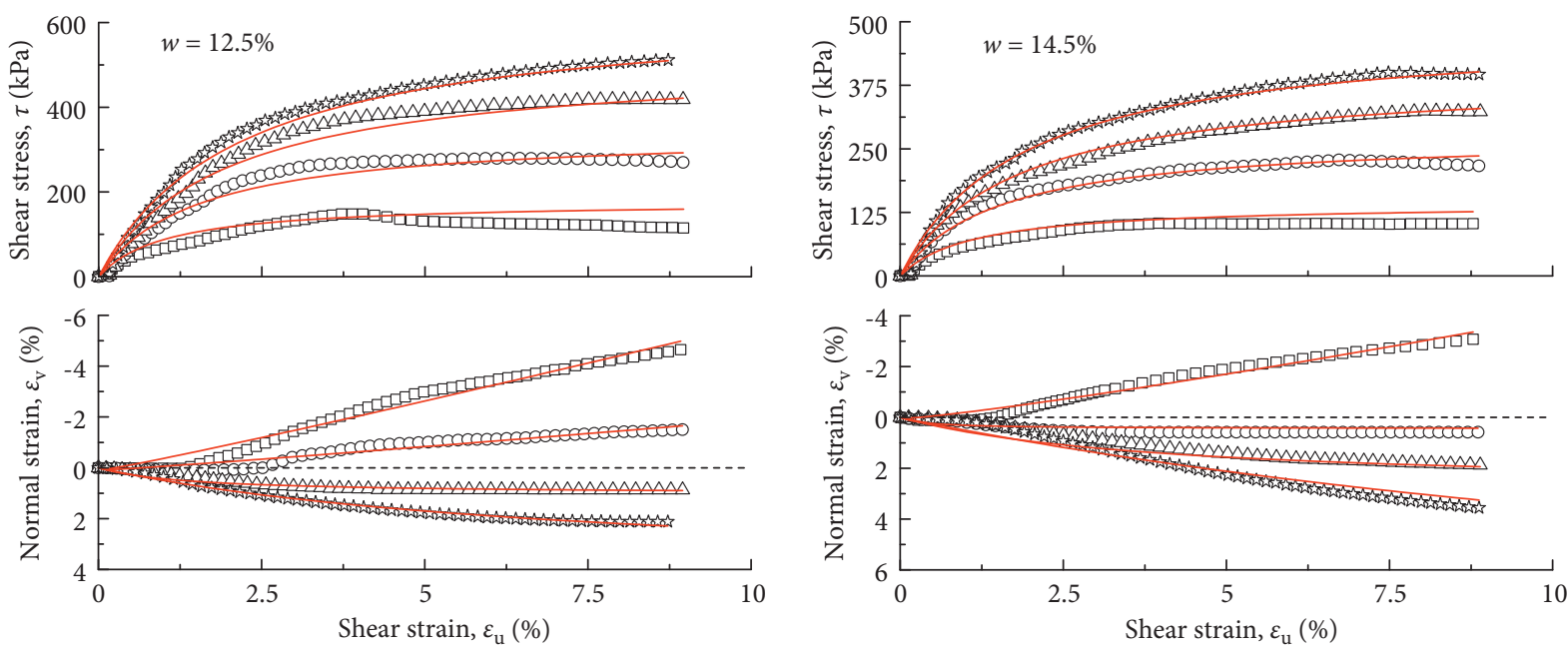
口 $\sigma_{\mathrm{n}}=200 \mathrm{kPa}$
$\Delta \sigma_{\mathrm{n}}=600 \mathrm{kPa}$
○ $\sigma_{\mathrm{n}}=400 \mathrm{kPa}$
* $\sigma_{\mathrm{n}}=800 \mathrm{kPa}$
口 $\sigma_{\mathrm{n}}=200 \mathrm{kPa}$
$\Delta \sigma_{\mathrm{n}}=600 \mathrm{kPa}$
○ $\sigma_{\mathrm{n}}=400 \mathrm{kPa}$
^ $\sigma_{\mathrm{n}}=800 \mathrm{kPa}$

(a)

(b)

Figure 9: Continued. 


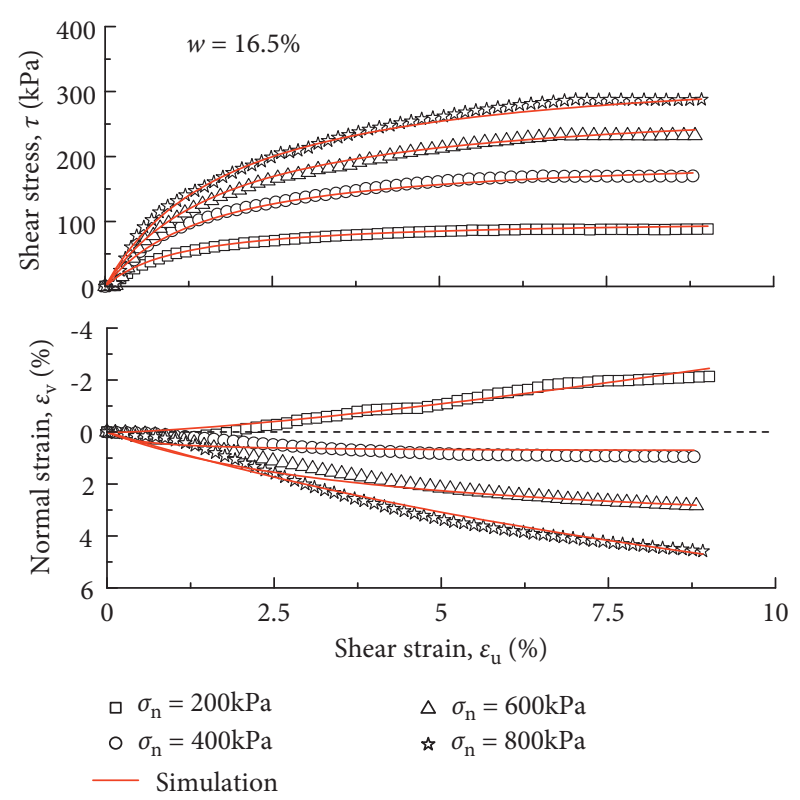

(c)
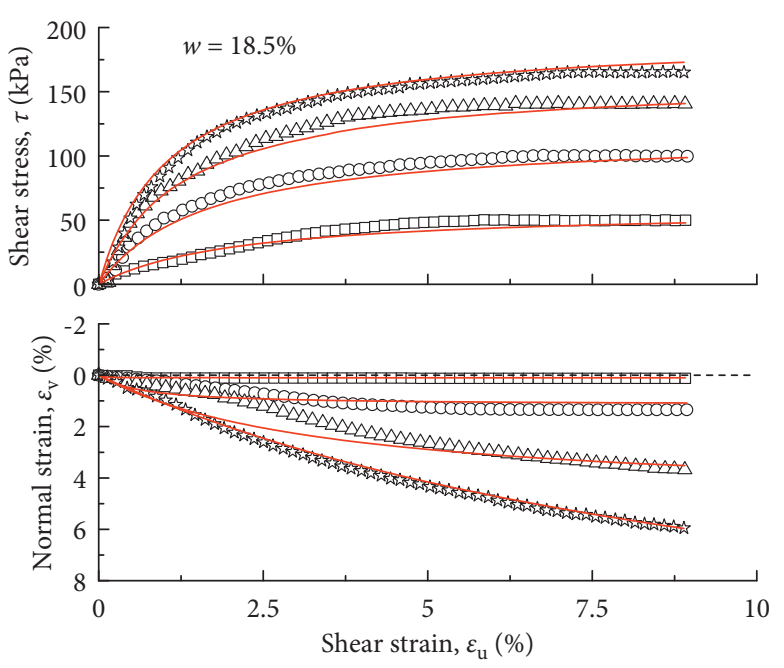

$$
\begin{array}{ll}
\text { } \sigma_{\mathrm{n}}=200 \mathrm{kPa} & \Delta \sigma_{\mathrm{n}}=600 \mathrm{kPa} \\
\circ \sigma_{\mathrm{n}}=400 \mathrm{kPa} & \text { ㅎ } \sigma_{\mathrm{n}}=800 \mathrm{kPa}
\end{array}
$$

Simulation

(d)

Figure 9: Comparison of test results with model simulations. (a) $w=12.5 \%$, (b) $w=14.5 \%$, (c) $w=16.5 \%$, and (d) $w=18.5 \%$.

\begin{tabular}{|c|c|c|c|c|c|}
\hline & $a_{\mathrm{L}}$ & $b_{\mathrm{L}}$ & $a_{\mathrm{E}}$ & $b_{\mathrm{E}}$ & $R^{2}$ \\
\hline$\varphi_{\mathrm{i}}$ & -350.91 & 79.35 & - & - & 0.98 \\
\hline$\varphi_{\mathrm{c}}$ & -296.55 & 63.43 & - & - & 0.99 \\
\hline$C_{\mathrm{i}}$ & -167.3 & 31.18 & - & - & 0.93 \\
\hline$C_{\mathrm{c}}$ & -1078.8 & 254.22 & - & - & 0.84 \\
\hline$K_{1}$ & -1.9 & 0.37 & - & - & 0.96 \\
\hline$n_{1}$ & - & - & 113.66 & 2.8 & 0.77 \\
\hline$R_{\mathrm{f}}$ & 0 & 0.83 & - & - & 0.92 \\
\hline$e_{1}$ & -7 & 1.15 & - & - & 0.84 \\
\hline$e_{2}$ & -6.35 & 1.8 & - & - & 0.84 \\
\hline$f_{1}$ & 13.75 & -3.24 & - & - & 0.99 \\
\hline$f_{2}$ & - & - & 0.000003 & -9.94 & 0.99 \\
\hline$k_{1}$ & 4.25 & 0.83 & - & - & 0.95 \\
\hline$k_{2}$ & - & - & 22.15 & -7.75 & 0.97 \\
\hline$n_{2}$ & 6.88 & -0.81 & - & - & 0.97 \\
\hline
\end{tabular}

TABLE 4: Best-fitting relationship between model parameters and water content.

functions, and the fitting results are listed in Table 4. $a_{\mathrm{L}}$ and $b_{\mathrm{L}}$ are linear function fitting parameters, and $a_{\mathrm{E}}$ and $b_{\mathrm{E}}$ are exponential function fitting parameters.

From Table 4 , it can be noted that the values of correlation coefficient $R^{2}$ are extremely high, which means that model parameters can be quickly estimated by water content.

\section{Conclusions}

This paper studied the shear behavior of contact clay-concrete cushion interface of Lianghekou dam. A series of direct shear tests are conducted to examine the shear behavior between high plasticity clay and concrete, and a nonlinear elastic model is proposed for the clay-concrete interface. The following conclusions can be drawn from the study:
(1) The water content and normal stress are significant factors affecting the shear behavior of the interface. The higher shear strength is related to lower water content and higher normal stress. The shear behavior exhibits a shear contraction trend with the increase of the normal stresses and water content.

(2) By comparing the shear strength of interface and clay, it is found that the interface makes sliding failure along the concrete surface when normal stress is less than critical normal stress, while shear failure occurs in clay matrix when normal stress is greater than critical normal stress.

(3) The shear strength of interface can be formulated by bifold-line type Mohr-Coulomb strength criterion, which is composed of shear strength of interface and clay. 
(4) A nonlinear elastic model is proposed to predict the shear behavior of the interface, which seems to be simpler and easy to understand. The parameters of the model have clear physical meanings and can be quickly estimated by water content.

\section{Data Availability}

The data used to support the findings of this study are available from the corresponding author upon request.

\section{Conflicts of Interest}

The authors declare that they have no conflicts of interest.

\section{Acknowledgments}

This work was financially supported by the National Key R\&D Plan (no. 2018YFC1508503), the Basic Scientific Research Funds in National Nonprofit Institutes (no. Y320004 and no.Y320005), and the National Natural Science Foundation of China (no. U1765203).

\section{References}

[1] B. Y. Zhang, Y. F. Wen, B. Z. Zhu, and Y. Yu, "Action mechanism and numerical simulation methods of soil structures and slope engineering: the state-of-the-art," China Civil Engineering Journal, vol. 49, no. 8, pp. 1-15, 2016.

[2] R. Y. Luo, W. Zhang, and L. Wang, "Effects of fineness and content of phosphorus slag on cement hydration, permeability, pore structure and fractal dimension of concrete," Fractals, vol. 29, no. 2, Article ID 2140004, 2021.

[3] D. Liu, H. Dai, and Z. Zhang, "Mechanical properties and damming behaviors of gravelly solidified soil for earth-rock dam core wall," Soil Dynamics and Earthquake Engineering, vol. 25, no. 4, pp. 1964-1973, 2021.

[4] L. Wang, X. Lu, L. S. Liu, and X. Jie, "Influence of MgO on the hydration and shrinkage behavior of low heat Portland cement-based materials via pore structural and fractal analysis," Fractal and Fractional, vol. 6, p. 40, 2022.

[5] J. G. Potyondy, "Skin friction between various soils and construction materials," Géotechnique, vol. 11, no. 4, pp. 339-353, 1961.

[6] C.-S. Tang, B. Shi, and L.-Z. Zhao, "Interfacial shear strength of fiber reinforced soil," Geotextiles and Geomembranes, vol. 28, no. 1, pp. 54-62, 2010.

[7] J. Huang, W. Li, and D. Huang, "Fractal analysis on pore structure and hydration of magnesium oxysulfate cements by first principle, thermodynamic and microstructure-based methods," Fractal and Fractional, vol. 5, no. 4, p. 164, 2021.

[8] V. Fioranvante, "On the shaft friction modelling of nondisplacement piles in sand," Soils and Foundations, vol. 42, no. 2, pp. 23-33, 2002.

[9] J. T. DeJong and Z. J. Westgate, "Role of initial state, material properties, and confinement condition on local and global soil-structure interface behavior," Journal of Geotechnical and Geoenvironmental Engineering, vol. 135, no. 11, pp. 16461660, 2009.

[10] E. Evgin and K. Fakharian, "Effect of stress paths on the behaviour of sand-steel interfaces," Canadian Geotechnical Journal, vol. 33, no. 8, pp. 853-865, 1996.
[11] G. Zhang, L. Wang, and J.-m. Zhang, "Monotonic and cyclic modeling of interface between geotextile and gravelly soil," International Journal for Numerical and Analytical Methods in Geomechanics, vol. 34, no. 13, pp. 1346-1361, 2010.

[12] N. Yavari, A. M. Tang, J. M. Pereira, and G. Hassen, "Effect of temperature on the shear strength of soils and soil/structure interface," Canadian Geotechnical Journal, vol. 53, no. 7, pp. 1186-1194, 2016.

[13] S. Ganesan, M. Kuo, and M. Bolton, "Influences on pipeline interface friction measured in direct shear tests," Geotechnical Testing Journal, vol. 37, no. 1, pp. 1-13, 2014.

[14] L. Wang, X. M. Zeng, H. M. Yang, and L. Xingdong, "Investigation and application of fractal theory in cement-based materials: a review," Fractal and Fractional, vol. 5, no. 4, p. 247, 2021.

[15] H. Coyle and I. Sulaiman, "Skin friction for steel piles in sand," Journal of the Soil Mechanics and Foundations Division, vol. 92, no. 2, pp. 261-278, 1967.

[16] M. Uesugi and H. Kishida, "Frictional resistance at yield between dry sand and mild steel," Soils and Foundations, vol. 26, no. 4, pp. 139-149, 1986.

[17] M. Sharma, M. Samanta, and S. Sarkar, "A study on interface shear behaviour of soil nails from pullout and direct shear tests," International Journal of Physical Modelling in Geotechnics, vol. 20, no. 1, pp. 24-37, 2020.

[18] V. J. Vineetha and K. Ganesan, "Interface friction between glass fibre reinforced polymer and gravel soil," Advanced Materials Research, vol. 984-985, no. 1, pp. 707-710, 2014.

[19] M. Uesugi, H. Kishida, and Y. Tsubakihara, "Behavior of sand particles in sand-steel friction," Soils and Foundations, vol. 28, no. 1, pp. 107-118, 1988.

[20] Y. Tsubakihara and H. Kishida, "Frictional behaviour between normally consolidated clay and steel by two Direct shear type apparatuses," Soils and Foundations, vol. 33, no. 2, pp. 1-13, 1993.

[21] F. Tatsuoka and O. Haibara, "Shear resistance between sand and smooth or lubricated surfaces," Soils and Foundations, vol. 25, no. 1, pp. 89-98, 1985.

[22] M. Feligha and F. Hammoud, "Experimental investigation of frictional behavior between cohesive soils and solid materials using direct shear apparatus," Geotechnical \& Geological Engineering, vol. 34, no. 2, pp. 567-578, 2015.

[23] A. Taha and M. Fall, "Shear behavior of sensitive marine claysteel interfaces," Acta Geotechnica, vol. 9, no. 6, pp. 969-980, 2014.

[24] T. B. Hamid and G. A. Miller, "Shear strength of unsaturated soil interfaces," Canadian Geotechnical Journal, vol. 46, no. 5, pp. 595-606, 2009.

[25] C. Zeng, X. Li, and Y. Wang, "Behaviour of the interface between stored wheat and a steel silo under static and cyclic loading conditions," Biosystems Engineering, vol. 190, no. 2, pp. 87-96, 2020.

[26] R. Al-Douri and H. Poulos, "Static and cyclic direct shear tests on carbonate sands," Geotechnical Testing Journal, vol. 15, no. 2, pp. 138-157, 1992.

[27] S. Pra-Ai and M. Boulon, "Soil-structure cyclic direct shear tests: a new interpretation of the direct shear experiment and its application to a series of cyclic tests," Acta Geotechnica, vol. 12, no. 1, pp. 107-127, 2017.

[28] Y. Tsubakihara, H. Kishida, and T. Nishiyama, "Friction between cohesive soils and steel," Soils and Foundations, vol. 33, no. 2, pp. 145-156, 1993. 
[29] Z. Z. Yin, Z. Hong, and G. H. Xu, "A study of deformation in the interface between soil and concrete," Computers and Geotechnics, vol. 17, no. 1, pp. 75-92, 1995.

[30] J. Dejong, M. Randolph, and D. White, "Interface load transfer degradation during cyclic loading: a microscale investigation," Soils and Foundations, vol. 43, no. 4, pp. 81-93, 2003.

[31] K. M. Wei, S. S. Chen, and G. Y. Li, "Application of a generalised plasticity model in high earthcore dam static and dynamic analysis," European Journal of Environmental and Civil Engineering, vol. 24, no. 2, pp. 1-34, 2018.

[32] G. W. Clough and J. M. Duncan, "Finite element analyses of retaining wall behavior," Journal of Soil Mechanics and Foundation Engineering, vol. 97, no. 12, pp. 1657-1673, 1971.

[33] J. E. Gómez, G. M. Filz, and R. M. Ebeling, "Extended hyperbolic model for sand-to-concrete interfaces," Journal of Geotechnical and Geoenvironmental Engineering, vol. 129, no. 11, pp. 993-1000, 2003.

[34] N. Navayogarajah, C. Desai, and P. Kiousis, "Hierarchical single surface model for static and cyclic behavior of interfaces," Journal of Engineering Mechanics, vol. 118, no. 5, pp. 990-1011, 1992.

[35] I. Shahrour and F. Rezaie, "An elastoplastic constitutive relation for the soil-structure interface under cyclic loading," Computers and Geotechnics, vol. 21, no. 1, pp. 21-39, 1997.

[36] H. Liu, E. Song, and H. I. Ling, "Constitutive modeling of soilstructure interface through the concept of critical state soil mechanics," Mechanics Research Communications, vol. 33, no. 4, pp. 515-531, 2006.

[37] Z. Rehman and G. Zhang, "Shear coupling effect of monotonic and cyclic behaviour of the interface between steel and gravel," Canadian Geotechnical Journal, vol. 56, no. 6, pp. 876-884, 2019.

[38] K. Fakharian and E. Evgin, "Elasto-plastic modelling of stresspath dependent behavior of interfaces," International Journal for Numerical and Analytical Methods in Geomechanics, vol. 24, no. 2, pp. 183-199, 2000.

[39] J. Liu, D. Zou, and X. Kong, "A three-dimensional statedependent model of soil-structure interface for monotonic and cyclic loadings," Computers and Geotechnics, vol. 61, no. 6, pp. 166-177, 2014.

[40] Z. Rehman and G. Zhang, "Three-dimensional elasto-plastic damage model for gravelly soil-structure interface considering the shear coupling effect - ScienceDirect," Computers and Geotechnics, vol. 129, no. 5, Article ID 103868, 2021.

[41] X. Chen, J. Zhang, Y. Xiao, and J. Li, "Effect of roughness on shear behavior of red clay - concrete interface in large-scale direct shear tests," Canadian Geotechnical Journal, vol. 52, no. 8, pp. 1122-1135, 2015.

[42] ASTM D5321, Standard Test Method for Determining the Shear Strength of Soil-Geosynthetic or Geosynthetic-Geosynthetic Interface by Direct Shear, ASTM, Pennsylvania, PA, USA, 2017.

[43] Y. Wang, X. Liu, M. Zhang, and X. Bai, "Effect of roughness on shear characteristics of the interface between silty clay and concrete," Advances in Civil Engineering, vol. 2020, no. 2, pp. 1-9, Article ID 8831759, 2020.

[44] ASTM D3080, Standard Test Method for Direct Shear Test of Soils under Consolidated Drained Conditions, ASTM, Pennsylvania, PA, USA, 2011.

[45] P. A. Vermeer, "Non-associated plasticity for soils, concrete and rock," Heron, vol. 29, no. 3, pp. 1-64, 1984.
[46] M. Lings and M. Dietz, "The peak strength of sand-steel interfaces and the role of dilation," Soils and Foundations, vol. 45, no. 6, pp. 1-14, 2005.

[47] A. Afzali-Nejad, A. Lashkari, and P. T. Shourijeh, "Influence of particle shape on the shear strength and dilation of sandwoven geotextile interfaces," Geotextiles and Geomembranes, vol. 45, no. 1, pp. 54-66, 2017.

[48] F. C. Liu, S. P. Shang, and H. D. Hai, "Study of shear properties of silty clay-concrete interface by simple shear tests," Chinese Journal of Rock Mechanics and Engineering, vol. 30, no. 8, pp. 1720-1728, 2011.

[49] C. S. Desai, M. M. Zaman, J. G. Lightner, and H. J. Siriwardane, "Thin-layer element for interfaces and joints," International Journal for Numerical and Analytical Methods in Geomechanics, vol. 8, no. 1, pp. 19-43, 1984.

[50] K. Peng, J. G. Zhu, S. R. Feng, and C. Cai, "Elasto-plastic constitutive model of interface incorporating strain softening and dilatancy," Chinese Journal of Rock Mechanics and Engineering, vol. 32, no. s2, pp. 3979-3986, 2013.

[51] D. C. Lu, L. Luo, and X. Wang, "Softening/hardening constitutive model for soil-structure interface and numerical implementation," Engineering Mechanics, vol. 34, no. 7, pp. 41-50, 2017.

[52] T. H. Lu and F. B. Bao, "A coupled constitutive model for interface thin-layer element," Chinese Journal of hydraulic Engineering, vol. 31, no. 2, pp. 71-75, 2000.

[53] A. Zhou and T. Lu, "Elasto-plastic constitutive model of soilstructure interface in consideration of strain softening and dilation," Acta Mechanica Solida Sinica, vol. 22, no. 2, pp. 80-88, 2009.

[54] X. F. Zeng, Z. B. Peng, J. He, and K. Peng, "Elasto-plastic constitutive model of soil-structure interface with slurry," Journal of Northeastern University, vol. 35, no. 6, pp. 890-893, 2014. 